\title{
Graphene oxide and reduced graphene oxide
} induced neural pheochromocytoma-derived $\mathrm{PCI} 2$ cell lines apoptosis and cell cycle alterations via the ERK signaling pathways

\author{
This article was published in the following Dove Press journal: \\ International Journal of Nanomedicine \\ 2 August 2017 \\ Number of times this article has been viewed
}

\section{Yiyuan Kang \\ Jia Liu \\ Junrong Wu \\ Qian Yin \\ Huimin Liang \\ Aijie Chen \\ Longquan Shao}

Nanfang Hospital, Southern Medical University, Guangzhou, People's

Republic of China
Correspondence: Longquan Shao Nanfang Hospital, Southern Medical University No 1838, Guangzhou Avenue North, Guangzhou, People's Republic of China

Tel $+86|598928392|$

Fax +862062787153

Email shaolongquan@smu.edu.cn

\begin{abstract}
Given the novel applications of graphene materials in biomedical and electronics industry, the health hazards of these particles have attracted extensive worldwide attention. Although many studies have been performed on graphene material-induced toxic effects, toxicological data for the effect of graphene materials on the nervous system are lacking. In this study, we focused on the biological effects of graphene oxide (GO) and reduced graphene oxide (rGO) materials on PC12 cells, a type of traditional neural cell line. We found that GO and rGO exerted significant toxic effects on PC12 cells in a dose- and time-dependent manner. Moreover, apoptosis appeared to be a response to toxicity. A potent increase in the number of PC12 cells at G0/G1 phase after GO and rGO exposure was detected by cell cycle analysis. We found that phosphorylation levels of ERK signaling molecules, which are related to cell cycle regulation and apoptosis, were significantly altered after GO and rGO exposure. In conclusion, our results show that GO has more potent toxic effects than $\mathrm{rGO}$ and that apoptosis and cell cycle arrest are the main toxicity responses to GO and rGO treatments, which are likely due to ERK pathway regulation.
\end{abstract}

Keywords: graphene oxide, reduced graphene oxide, PC12, cell cycle alterations, ERK pathway

\section{Introduction}

In recent years, the understanding of graphene materials has facilitated their applications in the biomedical field, where they are used as biosensors and delivery carriers, and in gene therapy. ${ }^{1,2}$ Moreover, graphene oxide (GO), which is chemically exfoliated from oxidized graphite, is a promising material for biological applications. In addition to $\mathrm{GO}$, reduced graphic oxide ( $\mathrm{rGO}$ ), the product obtained by treating $\mathrm{GO}$ under reducing conditions to reduce its oxygen content, is also utilized. ${ }^{3} \mathrm{rGO}$ has attracted significant interest in the fields of tissue engineering, molecular imaging, drug/gene delivery, ${ }^{4}$ and neural interfaces. ${ }^{5,6}$ Due to the increase in wide applications of GO materials, more safety information should be obtained in an effort to clearly understand how cells respond on exposure to graphene derivatives.

Recent studies have focused on the graphene-induced toxicological profile. An in vivo study showed that after intravenous administration, GO mainly localized in the lung, liver, and spleen, where significant toxic damage was observed. ${ }^{7}$ Moreover, oxidative stress is believed to be a major toxic response to $\mathrm{GO}$ at toxic doses, 
and the generation of reactive oxygen species (ROS) is considered its main factor. ${ }^{2,8-10}$ The blood-brain barrier (BBB) has an intricate physical and molecular structure that provides the proper microenvironment for neuronal cell activity to withstand the penetration of foreign matter, including graphene materials. However, in recent decades, the penetration of materials through the $\mathrm{BBB}$, especially nanomaterials, has become possible due to their tiny size. Graphene materials are also believed to translocate into the brain through the BBB. ${ }^{11}$

Although some toxicological information on graphene materials has been obtained in vitro and in vivo, these data are limited and partial. Moreover, as neurotoxicological information on $\mathrm{GO}$ and $\mathrm{rGO}$ remains obscure, more research is required. In this study, PC12 cells, a traditional cell line for neuroscience studies, were selected for toxicological analysis. To examine the effects of oxidation state on the toxic response to $\mathrm{GO}$, we detected toxicological differences in GO and rGO materials. Moreover, we found that other biological processes, such as the cell cycle, were impacted by the exposure to $\mathrm{GO}$ and $\mathrm{rGO}$, and related molecular mechanisms were explored.

\section{Materials and methods}

\section{Material preparation and characterization}

GO was purchased from Sigma-Aldrich (CAS Number 763713; St Louis, MO, USA), and rGO was purchased from XFNANO (CAS Number 7440-44-0; Nanjing, People's Republic of China). GO and rGO nanosheets were characterized by atomic force microscopy (AFM, MFP-3D-S; Asylum Research, Santa Barbara, CA, USA), Raman spectroscopy (Dimension Edge; Bruker Nano Surfaces, Santa Barbara, CA, USA), and zeta-potential and particle size analysis (performed using dynamic light scattering [DLS]) measurements (Zetasizer Nano ZS; Malvern Instruments, Malvern, UK). $\mathrm{GO}$ and rGO were dispersed in ultrapure water to prepare stock solutions $(500 \mu \mathrm{g} / \mathrm{mL})$. The stock solution was sonicated for $2 \mathrm{~h}(40 \mathrm{kHz})$ and diluted to different concentrations with complete culture medium just prior to cell exposure.

\section{Cell culture}

The immortalized PC12 cell line (The Cell Bank of the Shanghai Infrastructure for Public Research and Development of the Chinese Academy of Medical Sciences, Shanghai, People's Republic of China) was cultured in Dulbecco's Modified Eagle's Medium (Thermo Fisher Scientific, Waltham, MA, USA) containing 10\% fetal bovine serum
(Thermo Fisher Scientific) and 1\% antibiotic/antimycotic solution (Thermo Fisher Scientific). Cells were incubated at $37^{\circ} \mathrm{C}$ with $5 \% \mathrm{CO}_{2}$ in a $95 \%$ humidified atmosphere, and the culture medium was replaced every other day.

\section{Cell proliferation assay}

Cell viability was determined using the cell counting kit- 8 (CCK-8) assay (Dojindo Molecular Technologies, Kumamoto, Japan). Cells were seeded in 96-well plates at a density of 5,000 cells/well. GO and rGO nanoparticles (NPs) were added at concentrations of $5,10,20,40,60,80$, and $100 \mu \mathrm{g} / \mathrm{mL}$, and the plates were incubated for $6,12,24$, and $48 \mathrm{~h}$ at $37^{\circ} \mathrm{C}$ with $5 \% \mathrm{CO}_{2}$. The control group was left untreated. For the CCK-8 test, $110 \mu \mathrm{L}$ detection reagent was added to each well, and the 96-well plates were incubated for an additional $2 \mathrm{~h}$ at $37^{\circ} \mathrm{C}$. To prevent NPs from interfering in this analytical assay, an empty 96-well plate was prepared. The optical density of each well was measured at $450 \mathrm{~nm}$ using a microplate reader (SpectraMax M5; Molecular Devices, Sunnyvale, CA, USA). There were six replicates for each treatment.

\section{Annexin $\mathrm{V}$ analysis by flow cytometry}

Cells were cultured in a 12-well plate at a density of 30,000 cells/well to reach confluency. After treatments with GO and rGO NPs, the cells were washed with $1 \mathrm{X}$ phosphate-buffered saline (PBS) and collected using ethylenediaminetetraacetic acid (EDTA)-free trypsin. The cells were resuspended in $1 \mathrm{X}$ PBS at a concentration of 25,000 cells $/ \mathrm{mL}$ and centrifuged at $1,000 \times g$. The cells were then stained with $5 \mu \mathrm{L}$ fluorescein isothiocyanate-Annexin $\mathrm{V}$ and $1 \mu \mathrm{L}$ propidium iodide (PI; $100 \mu \mathrm{g} / \mathrm{mL}$ ) (Invitrogen, Carlsbad, CA, USA) protected from light at room temperature. Finally, the cells were mixed with $400 \mu \mathrm{L}$ of $1 \mathrm{X}$ binding buffer and analyzed immediately by flow cytometry (BD FACSAria III; BD, Franklin Lakes, NJ, USA).

\section{Cell cycle analysis}

The Cell Cycle Detection Kit (KeyGen Biotech, Nanjing, People's Republic of China) was used to detect the DNA content of each cell. PC12 cells were starved for $12 \mathrm{~h}$ before treatments with GO and rGO NPs. At the end of the treatment, the cells were collected using $0.25 \%$ EDTA/trypsin and washed twice with $1 \mathrm{X}$ PBS. Then, $70 \%$ ethanol was used to fix the cells at $4^{\circ} \mathrm{C}$ for $12 \mathrm{~h}$. The cells were incubated with $100 \mu \mathrm{L}$ of RNase for $30 \mathrm{~min}$ at $37^{\circ} \mathrm{C}$, and then $400 \mu \mathrm{L}$ PI was added, followed by incubation at room temperature protected from light for $30 \mathrm{~min}$. Fluorescence values were 
analyzed by flow cytometry (BD FACSAria III; BD), and the percentage of cells in each phase of the cell cycle (G0/G1, S, and $\mathrm{G} 2 / \mathrm{M}$ ) was calculated using Modifit.

\section{Confocal microscopy}

Cells were seeded on glass coverslips and cultured in the presence of GO and rGO NPs for $24 \mathrm{~h}$. At the end of the treatment, the cells were washed twice with $1 \mathrm{X}$ PBS, fixed with $3.7 \%$ paraformaldehyde in PBS, permeabilized with $0.1 \%$ Triton $\mathrm{X}-100$, and preincubated with PBS containing 5\% bovine serum albumin. Then, cells were incubated for $1 \mathrm{~h}$ with rhodamine-phalloidin (1:4,000) in the dark, and the cell nuclei were stained with Hoechst 33342 for 20 min and examined using an FV10i confocal microscope (Olympus, Tokyo, Japan).

\section{Western blot analysis}

After treatments with GO and rGO NPs, cells were washed twice with PBS, and then lysis buffer (KeyGen Biotech) containing a protease inhibitor and phosphatase inhibitors was added on ice. The cells were scraped and collected into centrifuge tubes, the supernatant was transferred to another tube after centrifugation, and the protein concentration was determined using the bicinchoninic acid (BCA) protein assay (Pierce BCA Protein Assay Kit; Thermo Fisher Scientific). An equal amount of protein $(20 \mu \mathrm{g} /$ well $)$ was separated by $10 \%$ sodium dodecyl sulfate polyacrylamide gel electrophoresis. The proteins were transferred to polyvinylidene difluoride membranes (Merck Millipore, Darmstadt, Germany), which were then washed with tris buffered saline, with tween-20 (TBST) (20 mM Tris- $\mathrm{HCl}, 500 \mathrm{mM}$ $\mathrm{NaCl}$ [pH 7.5], and 0.01\% Tween-20). The membrane was blocked with TBST containing 5\% skim milk for $1 \mathrm{~h}$ at room temperature and then incubated overnight with primary antibodies from the ERK pathway kit (No \#9911; Cell Signaling Technology, Danvers, MA, USA), including antibodies against p-c-Raf(Ser338), p-MEK1/2 (Ser217/221), p-p44/42 MAPK (Thr202/Tyr204), p-p90RSK (Ser380), and GAPDH, at $4^{\circ} \mathrm{C}$. The secondary antibody, IRDye $800 \mathrm{CW}$-conjugated anti-rabbit/mouse IgG, was incubated with the membranes for $1 \mathrm{~h}$ at $37^{\circ} \mathrm{C}$ protected from light. Immunoreactive proteins were detected using the Odyssey infrared imaging system (Li-Cor, Lincoln, NE, USA).

\section{Statistical analysis}

Results are represented as the means \pm SEM. All data were statistically analyzed by analysis of variance. A homogeneityof-variance test was performed, and Bonferroni and Dunnett's
T3 tests were used when equal variance was assumed and when there was no homogeneity, respectively. $P$-values less than 0.05 were considered significant.

\section{Results \\ Characterization of GO and rGO nanosheets}

Figure 1 shows the representative AFM images of the GO and rGO samples. Most GO sheets exist as a single layer or as a few layers. The thickness of the GO layer was approximately $0.6 \mathrm{~nm}$, as indicated by AFM measurements, while rGO was thicker (approximately $0.9 \mathrm{~nm}$; Figure $1 \mathrm{~A}$ and $\mathrm{B}$ ). The GO surface had sags and crests, while rGO surface was more fluent when compared with GO (Figure 1A and B). The Raman spectra of the $\mathrm{GO} / \mathrm{rGO}$ materials used in the present study are shown in Figure $1 \mathrm{C}$. The D peak of GO can be located at $1,356.96 \mathrm{~cm}^{-1}$ and that of $\mathrm{rGO}$ at $1,345.46 \mathrm{~cm}^{-1}$, while the $\mathrm{G}$ peaks of $\mathrm{GO}$ and $\mathrm{rGO}$ are observed at 1,590.29 and $1,583.45 \mathrm{~cm}^{-1}$, respectively. The dispersity of GO and rGO was determined by zeta potential and DLS measurements. As shown in Table 1, the zeta potentials of GO and rGO were $-14.3 \pm 11.1$ and $-17.7 \pm 7.99 \mathrm{mV}$, respectively. The average size distributions of these two nanomaterials were 219 and $122.4 \mathrm{~nm}$, respectively.

\section{GO and $\mathrm{rGO}$ inhibited $\mathrm{PCI} 2$ proliferation and induced apoptosis}

PC12 cell viability was also examined after GO and rGO $(0,10,20,40,60,80$, and $100 \mu \mathrm{g} / \mathrm{mL})$ treatments (Figure 2). $\mathrm{GO}$ and $\mathrm{rGO}$ nanosheets resulted in dose- and time-dependent toxicity in PC12 cells, with GO being more cytotoxic than rGO. The cell viability was dramatically decreased following treatment with $20 \mu \mathrm{g} / \mathrm{mL} \mathrm{GO}$ and $\mathrm{rGO}$, and more than $50 \%$ of the PC12 cells died when the concentration of GO and rGO increased to 40 and $60 \mu \mathrm{g} / \mathrm{mL}$.

Apoptosis levels were detected after treatments with 50 and $100 \mu \mathrm{g} / \mathrm{mL}$ GO and $\mathrm{rGO}$ for $24 \mathrm{~h}$. The results showed that GO treatment induced high levels of apoptosis in a dose-dependent manner, whereas only a slight increase was observed following treatment with $\mathrm{rGO}$, which did not indicate significant apoptosis (Figure 3).

\section{$\mathrm{GO}$ and $\mathrm{rGO}$ induced $\mathrm{PCI} 2$ cell cycle} arrest

Cell proliferation depends on cell cycle progression; one of the most important biological processes, the cell cycle, includes a division phase and an interphase. Cells pass 

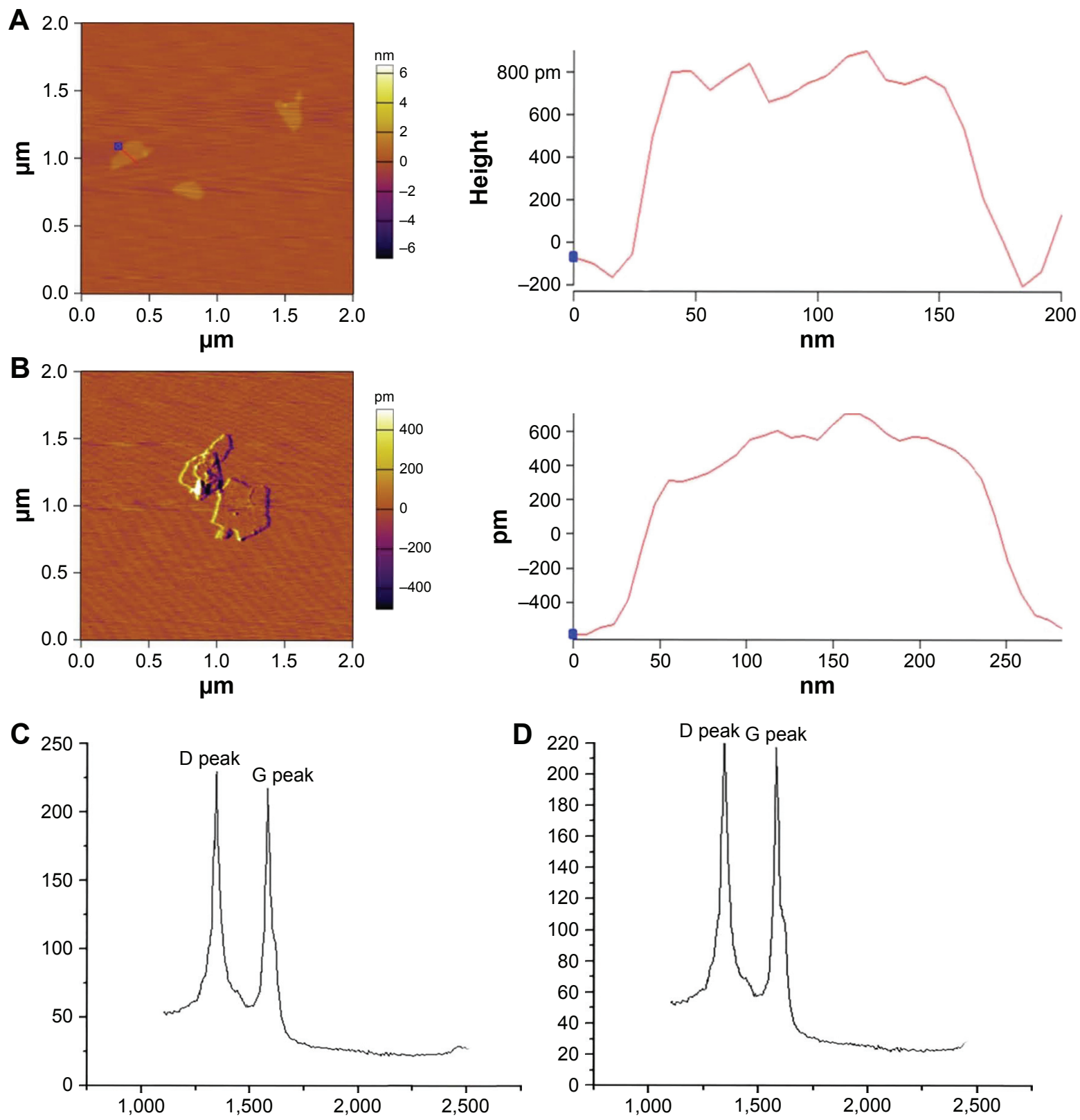

Figure I Characterization of GO and rGO nanosheets.

Notes: AFM characterization of the surface topography of (A) GO and (B) rGO. Raman spectroscopy of (C) GO and (D) rGO.

Abbreviations: GO, graphene oxide; rGO, reduced graphene oxide; AFM, atomic force microscopy.

through the G0/G1 phase (quiescence/gap 1) to the S phase (synthesis) and finally to the G2/M phase (gap 2 and mitosis, respectively). Cell division occurs during the mitosis phase (M phase), whereby a single cell divides into two cells.

Table I Particle size and zeta potential measurements of GO and rGO

\begin{tabular}{lll}
\hline Nanoparticles & Particle size $(\mathbf{n m})$ & Zeta potential $(\mathbf{m V})$ \\
\hline GO & 219 & $-14.3 \pm 1 \mathrm{I} . \mathrm{I}$ \\
rGO & 122.4 & $-17.7 \pm 7.99$ \\
\hline
\end{tabular}

Abbreviations: GO, graphene oxide; rGO, reduced graphene oxide.
A cell spends more time in interphase than other phases. G1 phase is the presynthetic phase, during which materials are largely produced and energy is stored for the ensuing DNA synthesis, which mainly occurs in S phase. G2 phase comprises the postsynthetic phase, during which mitosisrelated RNA and protein synthesis is completed.

Cell cycle analysis indicated that exposure to either $\mathrm{GO}$ or rGO led to the arrest of $\mathrm{PC} 12$ cells at the $\mathrm{G} 0 / \mathrm{G} 1$ phase of the cell cycle (Figure 4). The cells appeared normal in both the control and $10 \mu \mathrm{g} / \mathrm{mL}$ treatment groups; however, when cells were exposed to 20 and $50 \mu \mathrm{g} / \mathrm{mL} \mathrm{GO}$ or rGO, the number 

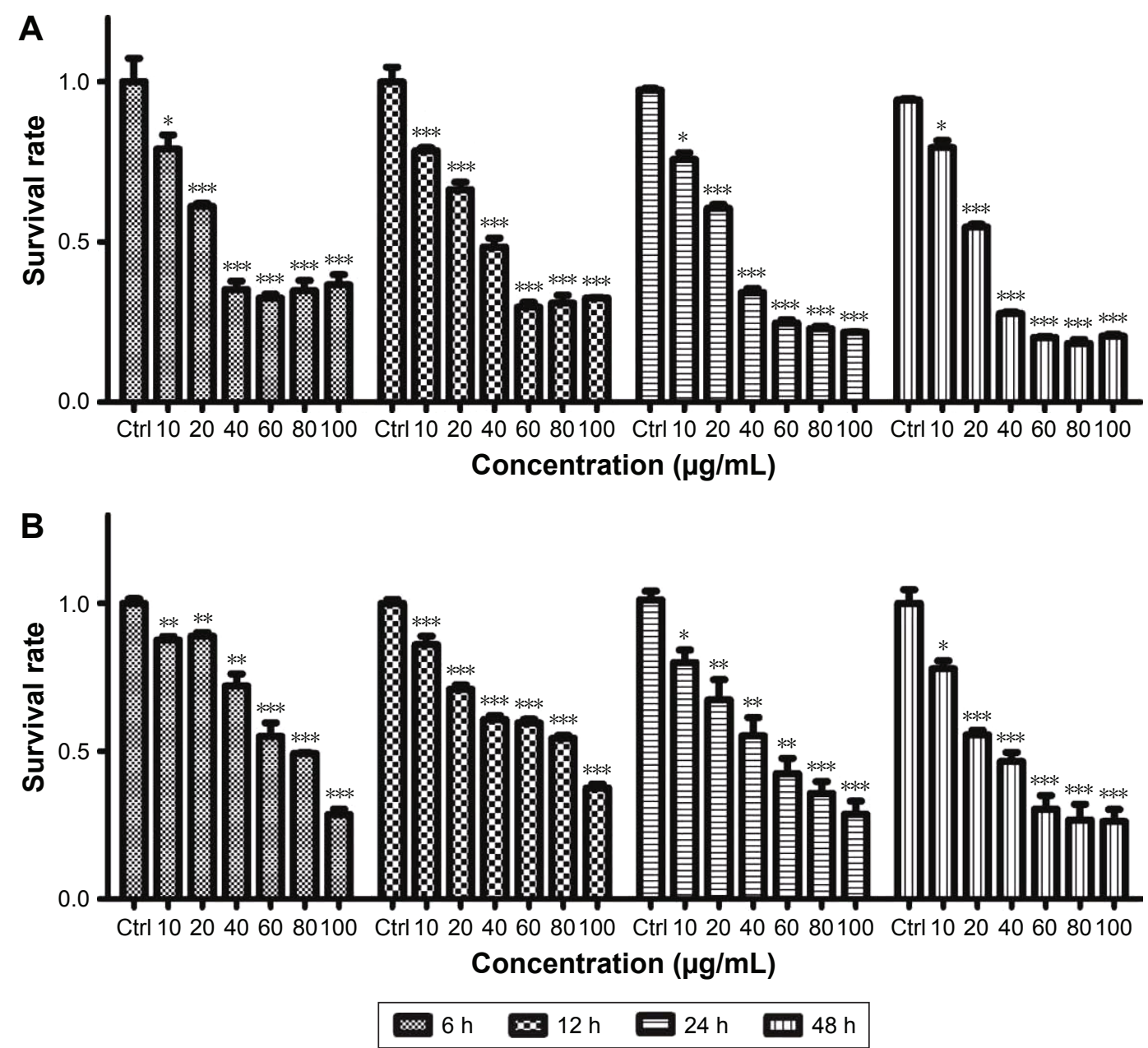

Figure $2 \mathrm{GO}$ and $\mathrm{rGO}$ nanosheets-induced alterations in $\mathrm{PCI} 2$ cell viability.

Notes: PCI 2 cells were treated with GO and rGO nanosheets at doses of $0,10,20,40,60,80$, or $100 \mu g / \mathrm{mL}$ for 6 , I2, 24, or 48 h. Cell viability was determined using the CCK-8 assay: (A) GO NPs and (B) rGO NPs. The results are presented as the mean \pm SEM from three independent experiments. $* P<0.05$, $* * P<0.0 \mathrm{I}$, and $* * * P<0.00 \mathrm{I}$. Abbreviations: Ctrl, control; GO, graphene oxide; rGO, reduced graphene oxide; CCK-8, cell counting kit-8; NPs, nanoparticles.

of cells in the G0/G1 phase increased, with a concomitant decrease of cells in $\mathrm{S}$ and $\mathrm{G} 2 / \mathrm{M}$ phase.

Immunocytochemistry for actin and nuclei (Figure 5) indicated that PC12 cells in the control group retained the ability to divide normally, but abnormal multinucleated cells were observed after the treatments with $50 \mu \mathrm{g} / \mathrm{mL}$ GO and $\mathrm{rGO}$.

\section{GO and rGO nanosheets induced changes in phosphorylation of ERK pathway proteins}

We hypothesized that the GO- and rGO-induced PC12 cell cycle arrest was due to altered phosphorylation levels of ERK pathway molecules, as this pathway plays an important role in cell cycle regulation. Western blot analysis (Figures 6 and 7) revealed significant changes in the phosphorylation levels of related upstream and downstream proteins of the ERK pathway. Following treatment with GO, we observed marked fluctuations in the phosphorylation levels. The level of p-MEK1/2, p-ERK, and p-p90RSK slightly decreased at $30 \mathrm{~min}$ or $1 \mathrm{~h}$, which then significantly increased, especially p-MEK1/2 and p-ERK, at $6 \mathrm{~h}$. These phosphorylation levels decreased to those of baseline (p-MEK1/2, p-ERK) or significantly lower than the control group (p-p90RSK). Moreover, a persistent increase in the level of p-c-Raf was observed. For the rGO group, we found results different from those for the GO group. The phosphorylation levels of MEK1/2 and ERK were increased at $30 \mathrm{~min}$ and then decreased to baseline (p-ERK) or lower than the control group (p-MEK1/2), whereas the level of p-p90RSK increased at $3 \mathrm{~h}$ and then decreased to lower than the control group. The phosphorylation levels of c-Raf, MEK1/2, and p90RSK were lower than those of the control group at 12 and $24 \mathrm{~h}$; however, the level of $\mathrm{p}$-ERK returned to baseline. 


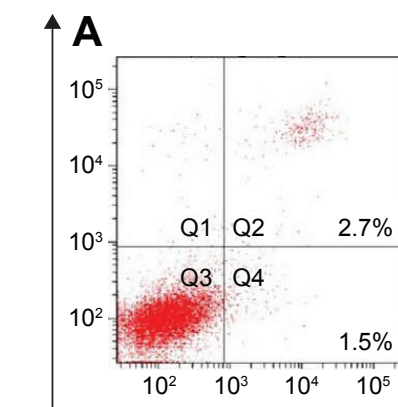

$\overline{\mathbf{n}}$

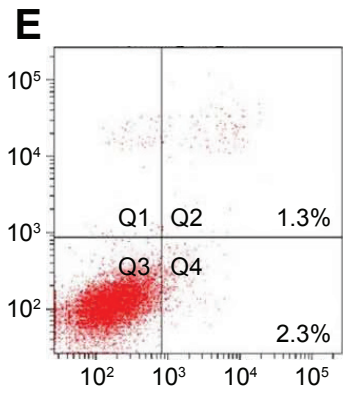

B

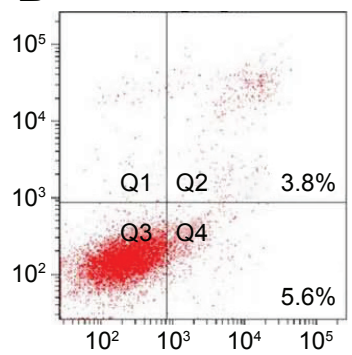

$\mathbf{F}$

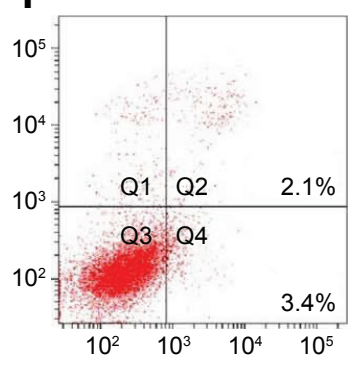

C

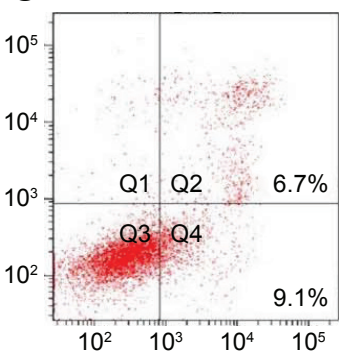

G

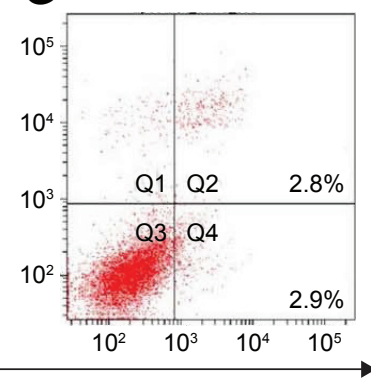

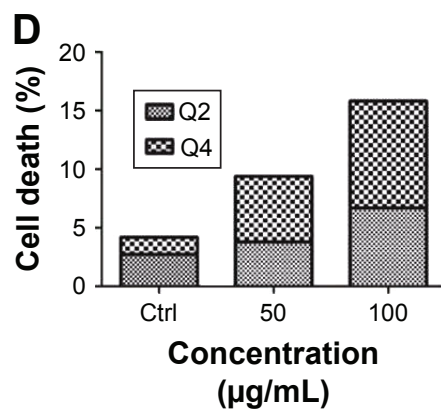

H

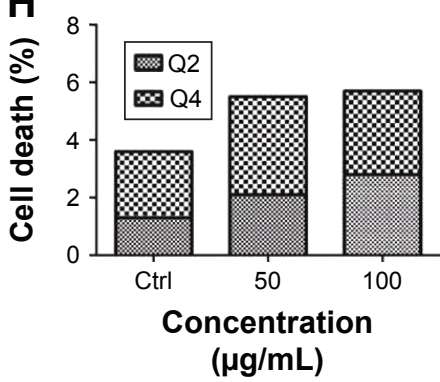

Annexin V

Figure $3 \mathrm{GO}$ and rGO nanosheets-induced PCI2 cell apoptosis.

Notes: PCI 2 cells were treated with GO and rGO nanosheets at doses of 0, 50, or $100 \mu \mathrm{g} / \mathrm{mL}$ for $24 \mathrm{~h}$ : (A and E) control; (B and C) PCI 2 cells treated with 50 or $100 \mu \mathrm{g} / \mathrm{mL}$

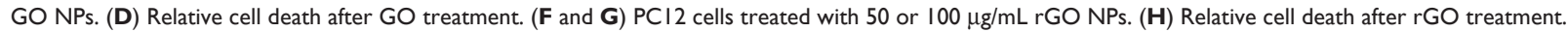

Abbreviations: Ctrl, control; GO, graphene oxide; rGO, reduced graphene oxide; NPs, nanoparticles; Pl, propidium iodide.

\section{Discussion}

Graphene family nanomaterials have been widely used as drug and gene delivery carriers and have been suggested for use in therapy of neurological diseases. ${ }^{12}$ These nanomaterials may exert differing degrees of toxicity in animals or cell models depending on the administration route or penetration through physiological barriers such as the BBB..$^{11,13,14}$ However, toxicological information on GO materials remains limited. In this study, we examined the neurotoxic effects of graphene family nanomaterials using the PC12 cell model.

When GO sheets interact with the cell membrane, the materials adhere to and wrap around the cell membrane and insert into the lipid bilayer so that they can be internalized into cells. ${ }^{15-17}$ The toxicological mechanisms of GO materials revealed in recent studies mostly involve the inflammatory response, oxidative stress, DNA damage, apoptosis, autophagy, and necrosis. ${ }^{18-20}$ Additional studies that used PC12 cells indicated that graphene and rGO caused reduced cell viability, mitochondrial dysfunction, lactate dehydrogenase release, and ROS generation., ${ }^{2,21}$ These oxidative stress responses have also been detected in other cells. ${ }^{22}$ Moreover, apoptosis was observed as a major toxic response, indicating that $\mathrm{GO}$ and $\mathrm{rGO}$ cause apoptosis in mouse lungs after inhalation, ${ }^{23}$ and some apoptosis-related proteins were activated following $\mathrm{GO}$ exposure in vitro. ${ }^{23,24}$ In our study, we examined PC12 cell viability using the CCK-8 assay, which revealed that GO and rGO induce a significant decrease in cell viability in both time- and dosedependent manner, with GO inducing more toxic effects than rGO. We also measured the level of apoptosis in PC12 cells following exposure to $\mathrm{GO}$ and $\mathrm{rGO}$, and found that $\mathrm{rGO}$ did not cause significant apoptosis at doses of 50 and $100 \mu \mathrm{g} / \mathrm{mL}$, though strong apoptosis levels were observed following GO exposure at the same doses. Similar results were observed in another study, in which GO caused a greater reduction in cell viability than rGO; the authors attributed these toxicity differences to the physicochemical properties of graphenebased materials, such as the density of functional groups, size, and conductivity. ${ }^{25}$ In our study, we found no significant size discrepancy between GO and rGO materials. However, the rGO surface was more fluent than that of the GO materials, which was likely one of the main reasons for the differences in toxicity between these two materials.

Considering the decrease in cell viability and apoptosis induced by GO and rGO, we next examined the cell cycle, as cell proliferation is dependent on cell cycle progression. Moreover, cell cycle alteration and apoptosis are in many cases related. ${ }^{26,27}$ Previous studies have indicated that 

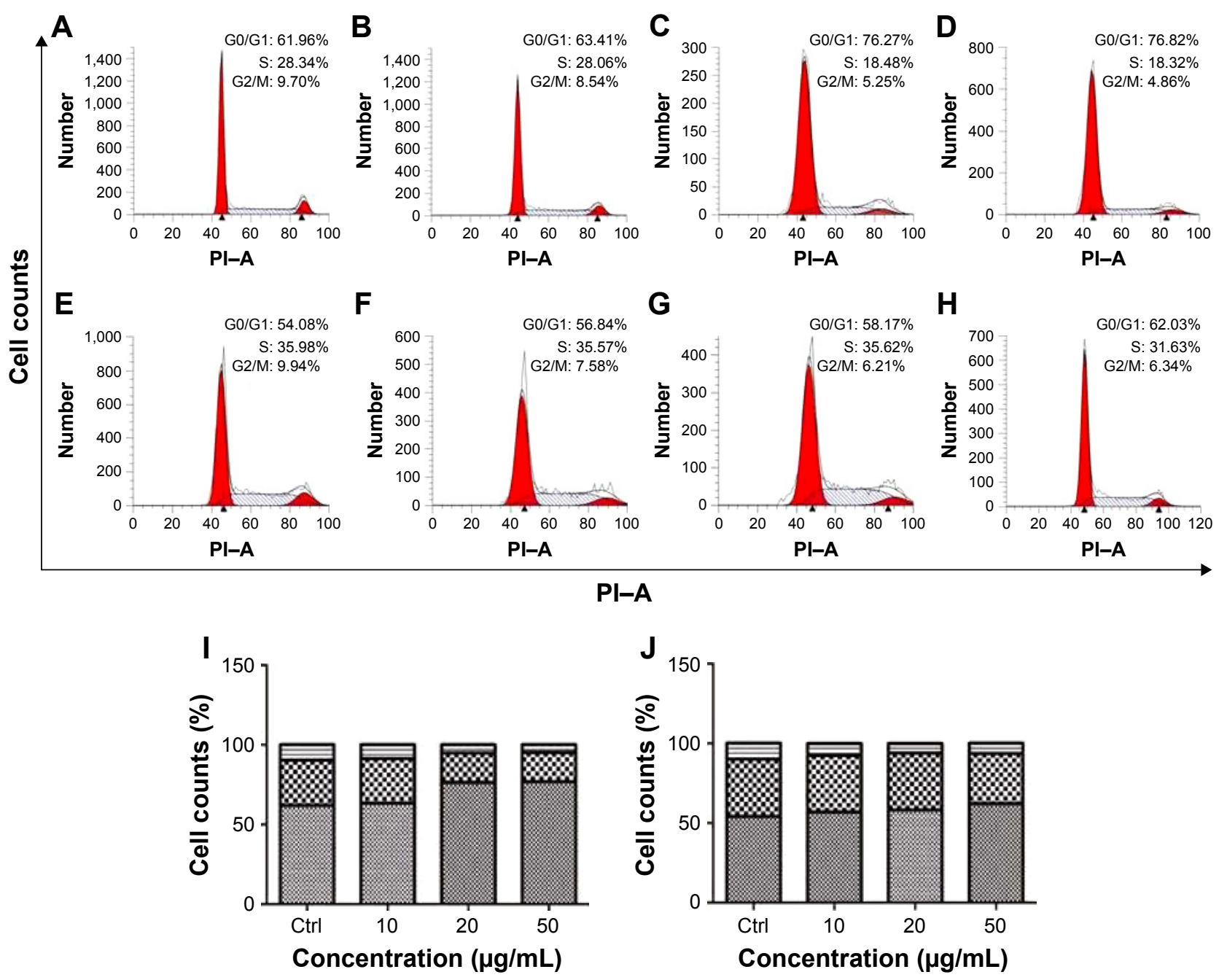

PI-A

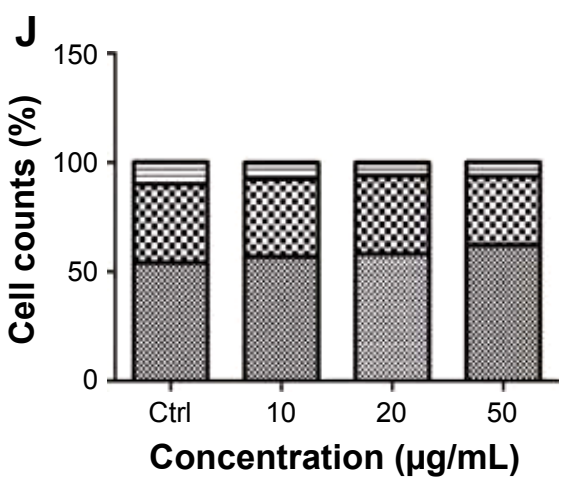

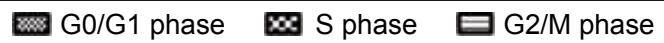

Figure $4 \mathrm{GO}$ and $\mathrm{rGO}$ induce $\mathrm{PCI} 2$ cell cycle arrest.

Notes: (A-D) PCI2 cells treated with GO nanosheets at $0,10,20$, or $50 \mu \mathrm{g} / \mathrm{mL}$ for $24 \mathrm{~h}$. (E-H) PCI2 cells treated with rGO nanosheets at $0,10,20$, or $50 \mu g / \mathrm{mL}$ for $24 \mathrm{~h}$. (I and J) Cell cycle analysis after GO and rGO treatment, respectively.

Abbreviations: Ctrl, control; GO, graphene oxide; rGO, reduced graphene oxide; PI-A, propidium iodide-Annexin V.

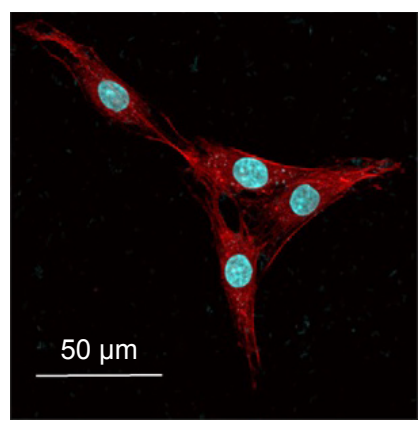

Control

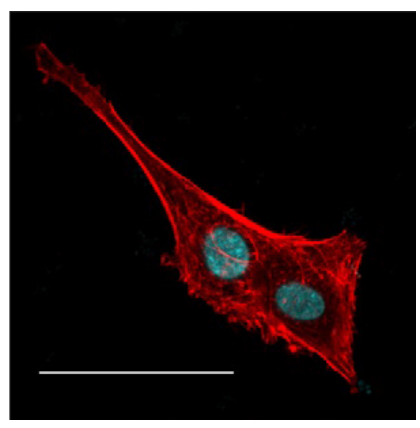

GO $50 \mu \mathrm{g} / \mathrm{mL} 24 \mathrm{~h}$

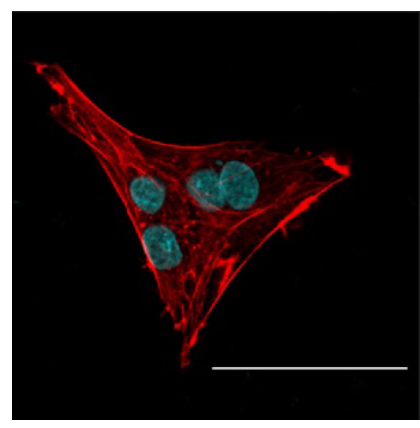

$\mathrm{rGO} 50 \mu \mathrm{g} / \mathrm{mL} 24 \mathrm{~h}$

Figure 5 Confocal microscopy analysis of GO- and rGO-induced PCI2 cell cycle arrest.

Notes: PCl2 cells were treated with $50 \mu \mathrm{g} / \mathrm{mL} \mathrm{GO}$ and rGO for 24 h. Cells were stained with rhodamine-phalloidin (red) and Hoechst 33342 (blue). Scale bar represents $50 \mu \mathrm{m}$.

Abbreviations: GO, graphene oxide; rGO, reduced graphene oxide. 


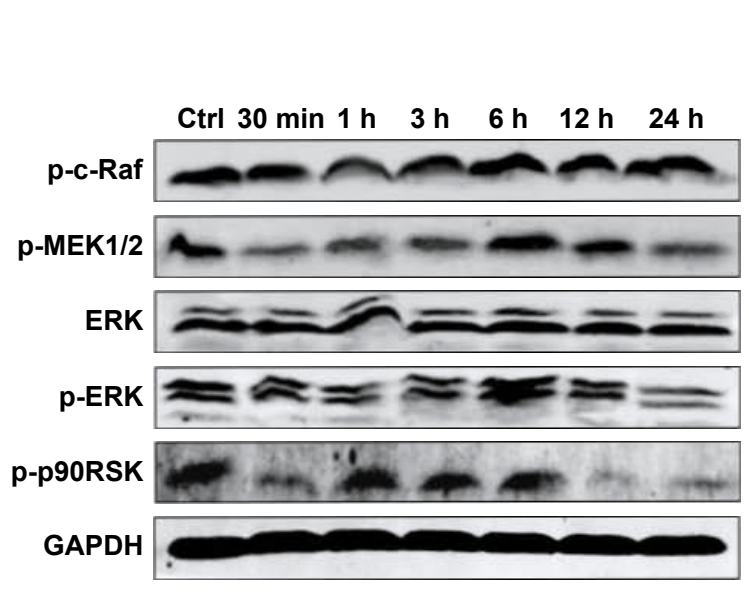

Figure 6 ERK phosphorylation levels after treatment with GO nanosheets.

Notes: PCI 2 cells were treated with GO nanosheets at a dose of $50 \mu \mathrm{g} / \mathrm{mL}$ for 30 min or I, 3, 6, I2, or 24 h. Total proteins were extracted, and the phosphorylation levels of ERK signaling pathway molecules were analyzed via Western blot. The results are presented as the mean $\pm S E M$ from three independent experiments. $* P<0.05$, $* * P<0.0$, and $* * * P<0.001$ compared with the control.

Abbreviations: Ctrl, control; GO, graphene oxide.

nanomaterials may lead to arrest of the cell cycle at various phases. ${ }^{28-30}$ Furthermore, many studies have shown that GO and rGO induce cell cycle arrest at the G0/G1 phase. ${ }^{31-33} \mathrm{In}$ our study, similar results were observed after treatments with $\mathrm{GO}$ and $\mathrm{rGO}$ at a dose of $50 \mu \mathrm{g} / \mathrm{mL}$. Moreover, $\mathrm{G} 0 / \mathrm{G} 1$ phase arrest was detected following treatment with $20 \mu \mathrm{g} / \mathrm{mL} \mathrm{GO}$, suggesting that GO causes more potent toxic effects than rGO. We also observed a significant decrease in the number of cells at G2/M phase, which may be related to abnormal growth and reveals an altered capacity for mitotic division, as evidenced by the appearance of two or more nuclei in one cell.

Limited data have indicated that $\mathrm{GO}$ and $\mathrm{rGO}$ induce cell cycle alterations. Matesanz et a ${ }^{32}$ attributed the GO-induced cell cycle alterations to the location of GO on F-actin filaments because actin microfilaments must be intact for G1 progression, S phase entry, and mitotic division. ${ }^{34}$ However, the detailed molecular mechanism remains unknown. Therefore, we explored changes in ERK signaling pathway molecules after exposure to $50 \mu \mathrm{g} / \mathrm{mL}$ GO and rGO. As an

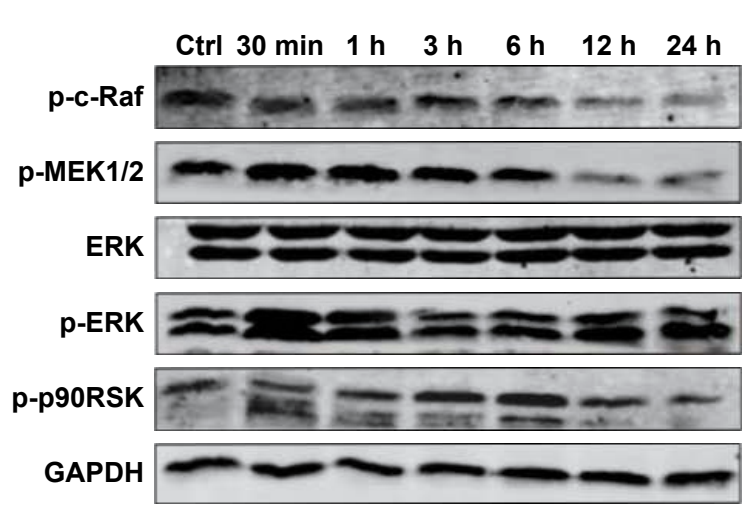

Figure 7 ERK phosphorylation levels after treatment with $\mathrm{rGO}$ nanosheets.

Notes: PCI 2 cells were treated with rGO nanosheets at a dose of $50 \mu \mathrm{g} / \mathrm{mL}$ for $30 \mathrm{~min}$ or I, 3, 6, I2, or 24 h. Total proteins were extracted, and the phosphorylation levels of ERK signaling pathway molecules were analyzed via Western blot. The results are presented as the mean $\pm S E M$ from three independent experiments. $* * P<0.0$ I, and $* * * P<0.00$ I compared with the control.

Abbreviations: Ctrl, control; rGO, reduced graphene oxide.
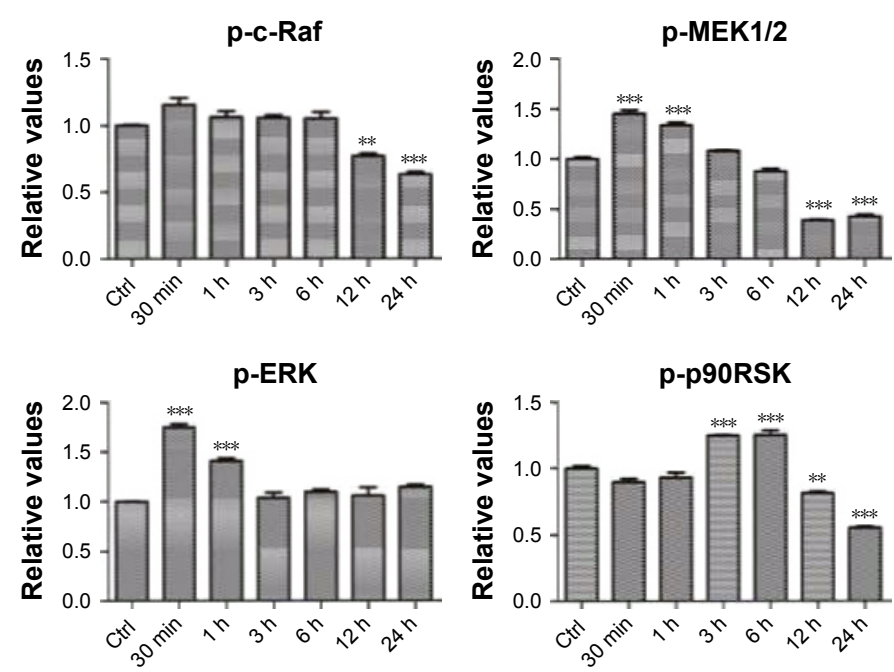
important protein kinase of the MAPK cascade, ERK controls numerous cellular processes, including proliferation, differentiation, development, stress response, and apoptosis. ${ }^{35}$ ERK regulates the transmission of many mitogenic and oncogenic signals that result in the promotion of cell proliferation. ERK appears to be required for many cells to pass the G1 restriction point and enter the $\mathrm{S}$ phase. ${ }^{36}$

Several studies have indicated that nanomaterials trigger specific biochemical and biological responses and that these toxic effects are caused by the generation of ROS, which likely induces apoptosis and other signaling pathways such as ERK and AKT (also named PKB). ${ }^{37-39}$ We hypothesized that $\mathrm{GO}$ and $\mathrm{rGO}$ induced cell cycle alterations via activation of the ERK signaling pathway. Our results showed altered phosphorylation levels of ERK signaling molecules after GO and rGO exposure. In rGO-treated cells, the phosphorylation levels of MEK1/2, ERK, and p90RSK first showed a significant increase, followed by a decrease to baseline levels (p-ERK) or to levels lower than that of the control group (p-c-Raf, p-MEK1/2, and p-p90RSK). These results showed the strong sequential activation effects of the ERK signaling pathway, which could be initiated as early as $30 \mathrm{~min}$. However, we observed entirely different results for GO: a persistent increase in p-c-Raf began at $3 \mathrm{~h}$, whereas the phosphorylation level of MEK1/2, ERK, and p90RSK increased significantly after an initial decline and ultimately returned to baseline. We attribute these interesting results to the exposure to a toxic dose $(50 \mu \mathrm{g} / \mathrm{mL})$ of GO. Our results indicate that GO at this dose induces significant apoptosis and cell cycle arrest, and this effect is not as strong for rGO. A previous study indicated that the ERK signaling pathway is activated as early as $5 \mathrm{~min} ;{ }^{40}$ therefore, we hypothesized that the ERK pathway was activated as early as $30 \mathrm{~min}$ after GO exposure and then decreased to baseline after $30 \mathrm{~min}$. However, exposure to $\mathrm{GO}$ at this dose caused potent toxic responses, including apoptosis, which likely initiated the ERK signaling pathway again after a 6-h exposure (these effects would not be observed following exposure to rGO, which did not initiate such toxic responses). ${ }^{35}$ Moreover, these GO- and rGO-induced effects on ERK activation are likely involved in changes throughout the cell cycle and in the cell death pathway.

\section{Conclusion}

Due to limited toxicological information of GO materials, we examined the neurotoxic effects of the graphene family. Our results indicated that GO exerts more potent toxic effects than $\mathrm{rGO}$, as evidenced by the reduced cell viability

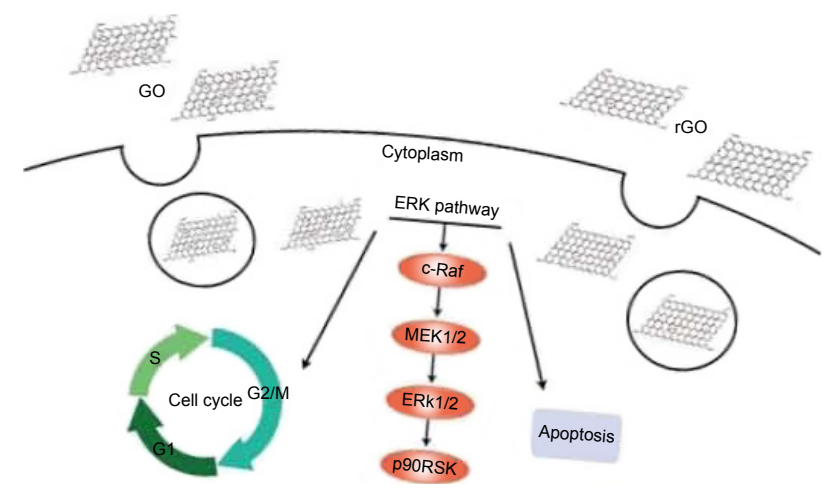

Figure 8 Schematic diagram of the GO and rGO nanosheets-induced effects on PCI 2 cell cycle arrest and apoptosis.

Note: Graphene nanosheets are endocytosed and activate the ERK signaling pathway to regulate the cell cycle and to induce apoptosis.

Abbreviations: $\mathrm{GO}$, graphene oxide; rGO, reduced graphene oxide.

and increased apoptosis and cell cycle arrest. We found that the GO- and rGO-induced cell cycle changes and apoptosis are related to the ERK signaling pathway, as illustrated in Figure 8. As some anticancer treatments are based on cell cycle arrest and induction of apoptosis, ${ }^{41}$ we believe that the GO- and rGO-induced effects on the cell cycle observed in the present study should be considered in future studies focused on cancer therapy. Moreover, GO and rGO may be used synergistically, which could increase the efficacy of targeted anticancer treatments. Our study provides new insights into the applications of graphene materials in the future, which warrants more attention.

\section{Acknowledgments}

This work was supported by the National Key Research and Development Program of China (2016YFC1102601, 2016YFC1102603), National Natural Science Foundation of China (51672122), and Natural Science Foundation of Guangdong Province (2015A030313299, 2016A030313673).

\section{Disclosure}

The authors report no conflicts of interest in this work.

\section{References}

1. Chung C, Kim YK, Shin D, Ryoo SR, Hong BH, Min DH. Biomedical applications of graphene and graphene oxide. Acc Chem Res. 2013; 46(10):2211-2224.

2. Zhang Y, Ali SF, Dervishi E, et al. Cytotoxicity effects of graphene and single-wall carbon nanotubes in neural phaeochromocytoma-derived PC12 cells. ACS Nano. 2010;4(6):3181-3186.

3. Bianco A, Cheng HM, Enoki T, et al. All in the graphene family a recommended nomenclature for two-dimensional carbon materials. Carbon. 2013;65(6):1-6.

4. Goenka S, Sant V, Sant S. Graphene-based nanomaterials for drug delivery and tissue engineering. J Control Release. 2014;173:75-88. 
5. Li N, Zhang X, Song Q, et al. The promotion of neurite sprouting and outgrowth of mouse hippocampal cells in culture by graphene substrates. Biomaterials. 2011;32(35):9374-9382.

6. Kim SM, Joo P, Ahn G, et al. Transparent conducting films based on reduced graphene oxide multilayers for biocompatible neuronal interfaces. J Biomed Nanotechnol. 2013;9(3):403-408.

7. Wang K, Ruan J, Song H, et al. Biocompatibility of graphene oxide. Nanoscale Res Lett. 2011;6(1):1-8.

8. Gollavelli G, Ling YC. Multi-functional graphene as an in vitro and in vivo imaging probe. Biomaterials. 2012;33(8):2532-2545.

9. Liu X, Sen S, Liu J, et al. Antioxidant deactivation on graphenic nanocarbon surfaces. Small. 2011;7(19):2775-2785.

10. Hu W, Peng C, Lv M, et al. Protein corona-mediated mitigation of cytotoxicity of graphene oxide. ACS Nano. 2011;5(5):3693-3700.

11. Mendonça MC, Soares ES, de Jesus MB, et al. Reduced graphene oxide induces transient blood-brain barrier opening: an in vivo study. J Nanobiotechnology. 2015;13:78.

12. Varga M, Wolff P, Wolter KJ. Biocompatibility study of three distinct carbon pastes for application as electrode material in neural stimulations and recordings. J Mater Sci Mater Med. 2017;28(2):30.

13. Liu Y, Xu LP, Dai W, Dong H, Wen Y, Zhang X. Graphene quantum dots for the inhibition of $\beta$ amyloid aggregation. Nanoscale. 2015;7(45):19060-19065.

14. Mendonça MC, Soares ES, de Jesus MB, et al. PEGylation of reduced graphene oxide induces toxicity in cells of the blood-brain barrier: an in vitro and in vivo study. Mol Pharm. 2016;13(11):3913-3924.

15. Xu M, Zhu J, Wang F, et al. Improved in vitro and in vivo biocompatibility of graphene oxide through surface modification: poly(acrylic acid)-functionalization is superior to PEGylation. ACS Nano. 2016; 10(3):3267-3281.

16. Sasidharan A, Panchakarla LS, Chandran P, et al. Differential nano-bio interactions and toxicity effects of pristine versus functionalized graphene. Nanoscale. 2011;3(6):2461-2464.

17. Kostarelos K, Novoselov KS. Materials science. Exploring the interface of graphene and biology. Science. 2014;344(6181):261-263.

18. Chatterjee N, Eom HJ, Choi J. A systems toxicology approach to the surface functionality control of graphene-cell interactions. Biomaterials. 2014;35(4):1109-1127.

19. Jaworski S, Sawosz E, Grodzik M, et al. In vitro evaluation of the effects of graphene platelets on glioblastoma multiforme cells. Int $J$ Nanomedicine. 2013;8:413-420.

20. Liu Y, Luo Y, Wu J, et al. Graphene oxide can induce in vitro and in vivo mutagenesis. Sci Rep. 2013;3:3469.

21. Zhang L, Xia J, Zhao Q, Liu L, Zhang Z. Functional graphene oxide as a nanocarrier for controlled loading and targeted delivery of mixed anticancer drugs. Small. 2010;6(4):537-544.

22. Lu CH, Zhu CL, Li J, Liu JJ, Chen X, Yang HH. Using graphene to protect DNA from cleavage during cellular delivery. Chem Commun (Camb). 2010;46(18):3116-3118.

23. Duch MC, Budinger GR, Liang YT, et al. Minimizing oxidation and stable nanoscale dispersion improves the biocompatibility of graphene in the lung. Nano Lett. 2011;11(12):5201-5207.

24. Li Y, Liu Y, Fu Y, et al. The triggering of apoptosis in macrophages by pristine graphene through the MAPK and TGF-beta signaling pathways. Biomaterials. 2012;33(2):402-411.

International Journal of Nanomedicine

\section{Publish your work in this journal}

The International Journal of Nanomedicine is an international, peerreviewed journal focusing on the application of nanotechnology in diagnostics, therapeutics, and drug delivery systems throughout the biomedical field. This journal is indexed on PubMed Central, MedLine, CAS, SciSearch $®$, Current Contents ${ }^{\circledR} /$ Clinical Medicine,
25. Liu S, Zeng TH, Hofmann M, et al. Antibacterial activity of graphite, graphite oxide, graphene oxide, and reduced graphene oxide: membrane and oxidative stress. ACS Nano. 2011;5(9):6971-6980.

26. Sun B, Geng S, Huang X, et al. Coleusin factor exerts cytotoxic activity by inducing $\mathrm{G} 0 / \mathrm{G} 1$ cell cycle arrest and apoptosis in human gastric cancer BGC-823 cells. Cancer Lett. 2011;301(1):95-105.

27. Alenzi FQ. Links between apoptosis, proliferation and the cell cycle. Br J Biomed Sci. 2004;61(2):99-102.

28. Jia L, Yiyuan K, Wei Z, et al. Ion-shedding zinc oxide nanoparticles induce microglial BV2 cell proliferation via the ERK and Akt signaling pathways. Toxicol Sci. Epub 2017 Jan 23.

29. Patel P, Kansara K, Senapati VA, Shanker R, Dhawan A, Kumar A. Cell cycle dependent cellular uptake of zinc oxide nanoparticles in human epidermal cells. Mutagenesis. 2016;31(4):481-490.

30. Kim KJ, Joe YA, Kim MK, et al. Silica nanoparticles increase human adipose tissue-derived stem cell proliferation through ERK1/2 activation. Int J Nanomedicine. 2015;10:2261-2272.

31. Khan M, Khan M, Al-Marri AH, et al. Apoptosis inducing ability of silver decorated highly reduced graphene oxide nanocomposites in A549 lung cancer. Int J Nanomedicine. 2016;11:873-883.

32. Matesanz MC, Vila M, Feito MJ, et al. The effects of graphene oxide nanosheets localized on F-actin filaments on cell-cycle alterations. Biomaterials. 2013;34(5):1562-1569.

33. Linares J, Matesanz MC, Feito MJ, et al. Influence of the covalent immobilization of graphene oxide in poly(vinyl alcohol) on human osteoblast response. Colloids Surf B Biointerfaces. 2016;138:50-59.

34. Fasshauer M, Iwig M, Glaesser D. Synthesis of proto-oncogene proteins and cyclins depends on intact microfilaments. Eur J Cell Biol. 1998; 77(3):188-195.

35. Rubinfeld H, Seger R. The ERK cascade: a prototype of MAPK signaling. Mol Biotechnol. 2005;31(2):151-174.

36. Ryu JM, Lee MY, Yun SP, Han HJ. Zinc chloride stimulates DNA synthesis of mouse embryonic stem cells: involvement of PI3K/Akt, MAPKs, and mTOR. J Cell Physiol. 2009;218(3):558-567.

37. Apopa PL, Qian Y, Shao R, et al. Iron oxide nanoparticles induce human microvascular endothelial cell permeability through reactive oxygen species production and microtubule remodeling. Part Fibre Toxicol. 2009;6:1

38. Piao MJ, Kim KC, Choi JY, Choi J, Hyun JW. Silver nanoparticles down-regulate Nrf2-mediated 8-oxoguanine DNA glycosylase 1 through inactivation of extracellular regulated kinase and protein kinase B in human Chang liver cells. Toxicol Lett. 2011;207(2):143-148.

39. Eom HJ, Choi J. Oxidative stress of $\mathrm{CeO} 2$ nanoparticles via p38-Nrf-2 signaling pathway in human bronchial epithelial cell, Beas-2B. Toxicol Lett. 2009;187(2):77-83.

40. Rauch J, Kolch W, Mahmoudi M. Cell type-specific activation of AKT and ERK signaling pathways by small negatively-charged magnetic nanoparticles. Sci Rep. 2012;2:868.

41. Sánchez I, Dynlacht BD. New insights into cyclins, CDKs, and cell cycle control. Semin Cell Dev Biol. 2005;16(3):311-321.

Journal Citation Reports/Science Edition, EMBase, Scopus and the Elsevier Bibliographic databases. The manuscript management system is completely online and includes a very quick and fair peer-review system, which is all easy to use. Visit http://www.dovepress.com/ testimonials.php to read real quotes from published authors. 